\title{
Effect of organic solvent and the lipid content on functionality of bovine lung protein isolates
}

\author{
José A. G. Arêas, ${ }^{*}$ Marcos J. C. Alcocer \\ Depto. de Alimentos e Nutrição Experimental da Faculdade de Ciências Farmacêuticas da USP, \\ Caixa Postal 66355, CEP 05389, São Paulo, SP, Brazil
}

\&

\author{
Eleonor M. A. Mota \\ Depto. de Farmácia Tecnológica e Administrativa da Universidade Federal da Bahia, Salvador, BA, Brazil
}

(Received 27 November 1992; revised version received and accepted 7 January 1993)

\begin{abstract}
Protein was isolated from bovine lung and extracted with organic solvents of varying polarities. Lipid represented $20 \%$ by weight of the total isolate, and the amount extracted depended on the polarity of the organic solvents employed. Phospholipids, cholesterol and free fatty acids were the lipid classes detected, phospholipids being the major component left after solvent extraction. Water absorption characteristics, solubility of the protein and superficial hydrophobicity were related to the amount of lipids left after solvent extraction. The results indicated that the lipids rather than the organic solvents used for lipid removal affected protein characteristics. Phospholipid-protein interactions seem to induce, on the protein, greater amounts of ordered conformation.
\end{abstract}

\section{INTRODUCTION}

Animal waste proteins are not fully employed as food because of their poor sensory characteristics (represented by their poor texture and unpleasant odour) and their high content of cholesterol and fat (Lawrie, 1991). Several attempts have been made to remove these constraints, without success. Organic solvent extraction of fat and cholesterol from offal tissues or isolates obtained from them can also eliminate off-flavours. However, this also reduces functional properties of the remaining protein (Gault \& Lawrie, 1980). This makes difficult the necessary improvement in their texture for further use as human food. Organic solvent-defatted abattoir waste has been investigated for use as food, after texturization through extrusion. However, the extruded products had poor texture and poor functionality, because of inadequate functional characteristics of the protein, which was probably caused by treatments previous to the extrusion processing. Interactions of the protein with lipids or organic solvents, which occur during protein isolation and solvent extraction, affected the extrusion of these materials, although their role in the process is still unclear (Arêas \& Lawrie,

* To whom correspondence should be addressed. On sabbatical leave at the Department of Biochemistry, University of Oxford, South Parks Road, Oxford, UK, OX1 3QU.
1984; Arêas, 1986a,b; Arêas \& Mota, 1990; Bastos \& Arêas, 1990; Bastos et al., 1991).

Functional properties are the ultimate consequence of protein structure. Water absorption properties, solubility, texturizability and superficial hydrophobicity, among other characteristics, are dependent on the protein three-dimensional conformation. Isolation procedures, solvent treatment and lipid still present in the preparations may affect structure and functional properties of proteins. Alkaline-acid isolation, for example, changes protein structure and functional behaviour (Whitaker \& Feeney, 1983). Organic solvents alter protein conformation in an aqueous environment, destabilizing its tertiary structure. As polarity of the organic solvent decreases, hydrophobic regions of protein molecule are more destabilized and, consequently, the solvent is more effective as a denaturant (Herkovits et al., 1970). On the other hand, in an anhydrous milieu (about $0.5 \%$ water) protein keeps its conformation and even maintains its biological activity at high temperatures when treated with polar organic solvents (Zaks \& Klibanov, 1984; Russel et al., 1989). Conformation of protein is also affected by the presence of lipids. Interaction of protein with lipids leads to greater exposure of some domains and protection of others, thus altering the thermal unfolding pattern of the protein (Lepock et al., 1990). All these molecular changes 
may occur during food processing, and modify conformation and affect functional characteristics of proteins. This has an enormous impact in their behaviour on subsequent use. Isolation of protein and fat removal are now gaining popularity as methods to add value to under-utilized animal tissues. It is therefore important to verify the consequences of these treatments on protein functional properties.

The objective of the present work was to provide some information about functional properties of the protein in lipid-rich lung isolates, after organic solvent treatment. A protein preparation isolated in alkaline medium was used and the dependence of some protein features on the polarity of the solvents employed in treatment and on the residual lipid after solvent extraction was investigated.

\section{MATERIALS AND METHODS}

\section{Raw material}

Bovine lungs (provided by a local abattoir) were minced immediately after slaughter, stored in individual polyethylene bags and frozen at $-30^{\circ} \mathrm{C}$.

\section{Preparation of protein isolates}

Protein isolates were prepared as previously described (Arêas, 1985). The tissue was homogenized in a Waring blender at $\mathrm{pH} 10.5$ with addition of $1 \mathrm{~N} \mathrm{NaOH}$ at $<10^{\circ} \mathrm{C}$. Protein was precipitated by lowering $\mathrm{pH}$ to $5 \cdot 0$ by addition of $1 \mathrm{~N} \mathrm{HCl}$ to the homogenate. After centrifugation, the precipitate was dialysed, freeze-dried and stored at $4{ }^{\circ} \mathrm{C}$ in sealed flasks. These preparations contain mainly myofibrillar protein and $20 \%$ lipids by weight (Gault \& Lawrie, 1980).

\section{Lipid determination on protein isolates}

The freeze-dried and desiccated protein isolate was homogenized (and later centrifuged at $500 \mathrm{~g}$ for $5 \mathrm{~min}$ ) at room temperature separately with solvents of varying polarities: carbon tetrachloride, chloroform, dichloromethane, isopropanol, ethanol and methanol (dielectric constants $2 \cdot 238,4.806,9.08,18 \cdot 30,24 \cdot 30$ and 33.62 , respectively (Weast \& Astle, 1980). Exhaustive extraction with each solvent was achieved after successive extraction, until no more phospholipids could be detected in the extract using a very sensitive colour reaction (Dittmer \& Lester, 1964). Residual lipid was extracted with chloroform-methanol-water as previously described (Folch et al., 1957; Christie, 1982). All solvent extracts were partitioned in Sephadex G-25 (Wuthier, 1966), vacuum-concentrated, freeze-dried and dissolved in chloroform-methanol $(2: 1)$ to a total volume of $10 \mathrm{ml}$.

Phospholipids in the extract were determined by two- dimensional thin-layer chromatography (TLC) separation and phosphorus analysis of spots (Rouser et al., 1970). To determine recovery, a chromato- graphically homogeneous egg lecithin was prepared as standard (Singleton et al., 1965). The various phospholipids were identified by $R_{\mathrm{f}}$ and by specific functional group reagent (Christie, 1982).

Free and total cholesterol were determined in the extracts by the ferric chloride-digitonin procedure (Courchaine et al., 1959).

The lipid in the extracts was fractionated into a neutral fraction and a phospholipid fraction on a silicic acid column. The lipids in the neutral fraction were separated by TLC and the triacylglycerol and free fatty acid bands were eluted and methylated with boron trifluoride-methanol (Christie, 1982). The fatty acid methyl esters were quantitated by gas-liquid chromatography (GLC) (fused silica capillary column, $0.25 \mathrm{~m}$ i.d., $15 \mathrm{~m}$ length, coated with Carbowax-20 in a chromatograph model 500, CG, Brazil), and the amount of each lipid class was calculated from the fatty acids.

\section{Hydratable sites on the protein through water vapour isotherms}

The isopiestic method (Bull \& Breese, 1968) was used to obtain the water sorption isotherms at $25^{\circ} \mathrm{C}$. The samples were desiccated over concentrated sulphuric acid at room temperature and $100 \mathrm{~mm} \mathrm{Hg}$, absolute, for $72 \mathrm{~h}$. Water activities were obtained by suitable dilution of sulphuric acid. Protein in the sample was determined by the micro-Kjeldahl method. Water monolayer calculated by the BET equation (Brunauer et al., 1938) was considered an index of hydratable sites on the protein (Lüscher-Mattli \& Rüegg, 1982).

\section{Circular dichroism spectra}

Protein solubility was assessed in several pH regions, conveniently buffered at the same ionic strength $(I=10)$. The samples $(20 \mathrm{mg})$ were stirred for $2 \mathrm{~min}$ with the buffer $(5.0 \mathrm{ml})$, and after $2 \mathrm{~h}$ standing were centrifuged for $15 \mathrm{~min}$ at $20000 \mathrm{~g}$. Absorbance at $280 \mathrm{~nm}$ of the supernatant and micro-Kjeldahl on both supernatant and initial samples were measured to determine protein solubility. Absorption spectra (not shown) of these preparations (Acta III spectrophotometer, Beckman, USA) have an absorption maximum at approximately $220 \mathrm{~nm}$, typical of the protein backbone, a shoulder between 250 and $300 \mathrm{~nm}$, attributed to aromatic residues, and a maximum of much lower intensity at about $400 \mathrm{~nm}$. Samples were diluted to obtain absorbancies at $220 \mathrm{~nm}$ in the range of $0.800-1.00$. Circular dichroism spectra of the protein were obtained in a Spectropolarimeter Cary-60 (Varian Aerograph, USA) adapted to circular dichroism. Cells with several path-lengths were tested and the cell position relative to the light source was varied to obtain the best conditions of path-length, cell position and recorder gain, which were then used on all samples. The spectra were recorded in the range 190 $300 \mathrm{~nm}$. 


\section{Superficial hydrophobicity of protein}

The method reported by Kato et al. (1984), which involved sodium dodecyl sulphate (SDS) binding, determination of the bound SDS by Methylene Blue complexation and chloroform extraction, was used.

\section{RESULTS AND DISCUSSION}

The lipid-protein preparation has the composition shown in Table 1. Phospholipids constituted $48 \cdot 6 \%$ by weight of the total lipids; cholesterol $18.2 \%$; free fatty acids $17.8 \%$; triacylglycerols $11.8 \%$; and cholesterol esters $4.9 \%$. The phospholipids were analysed, and phosphatidylcholine and sphingomyelin were found to be major components (Table 1). The lipids in the isolates were similar to those reported in lung tissues (Baxter et al., 1969; Rooney et al., 1974; Ryan et al., 1980; Alcocer \& Arêas, 1990).

Lipid extraction depended on polarity of the solvent (Fig. 1). Lipid extraction followed a hyperbolic pattern with solvent polarity expressed as a dielectric constant, as described previously (Arêas, 1985; Alcocer \& Arêas, 1990). Extraction was maximum with high-polarity solvents. The residual lipid after the solvent extraction (Fig. 1) is consistent with the amount in the extract.

Neutral lipids (cholesterol, cholesterol esters, triacylglycerols and free fatty acids) were equally extracted by the solvents. Figure 2 shows extraction of cholesterol. Extraction of phospholipids, however, was strongly dependent on solvent polarity, with maximum extraction by high-polarity solvents. The extraction pattern for all phospholipids was similar. Figure 2 shows data for sphingomyelin and phosphatidylcholine.

The effectiveness of lipid removal from the isolates depended on the strength of the lipid-protein interactions and on the ability of the solvent to disrupt them. Neutral lipids such as cholesterol, cholesterol esters, triaglycerols and free fatty acids complexed loosely to

Table 1. Composition of freeze-dried lung isolate ${ }^{a}$

\begin{tabular}{|c|c|}
\hline Moisture $(\%)^{b}$ & $0.54 \pm 0.14$ \\
\hline Ash $(\%)$ & $0.85 \pm 0.18$ \\
\hline Protein $(\%)^{c}$ & $81 \cdot 38 \pm 1 \cdot 35$ \\
\hline Lipid $(\%)^{d}$ & $20.45 \pm 2 \cdot 17$ \\
\hline Phosphatidylcholine $^{e}$ & $33.22 \pm 0.43$ \\
\hline Sphingomyelin $^{e}$ & $22.61 \pm 0.59$ \\
\hline Lysophosphatidylcholine $e^{e}$ & $13.08 \pm 1.70$ \\
\hline Lysophosphatidylethanolamine $e$ & $9.55 \pm 0.01$ \\
\hline Phosphatidylethanolamine $e^{e}$ & $6.44 \pm 0.64$ \\
\hline Phosphatidylserine $^{e}$ & $2 \cdot 18 \pm 0 \cdot 16$ \\
\hline Phosphatidylglycerol $^{e}$ & $1.38 \pm 0.22$ \\
\hline Phosphatidylinositol ${ }^{e}$ & $0 \cdot 89 \pm 0 \cdot 14$ \\
\hline Phosphatidic acid ${ }^{e}$ & $0.52 \pm 0.09$ \\
\hline Lysobisphosphatidic acide & $0.34 \pm 0.04$ \\
\hline
\end{tabular}

${ }^{a}$ Average of three determinations \pm SD.

${ }^{b}$ Determined by Karl Fischer method.

${ }^{c} \mathrm{~N} \times 6.25$.

${ }^{d}$ Determined by Folch wash.

${ }^{e}$ Percentage of the total phosphorus.

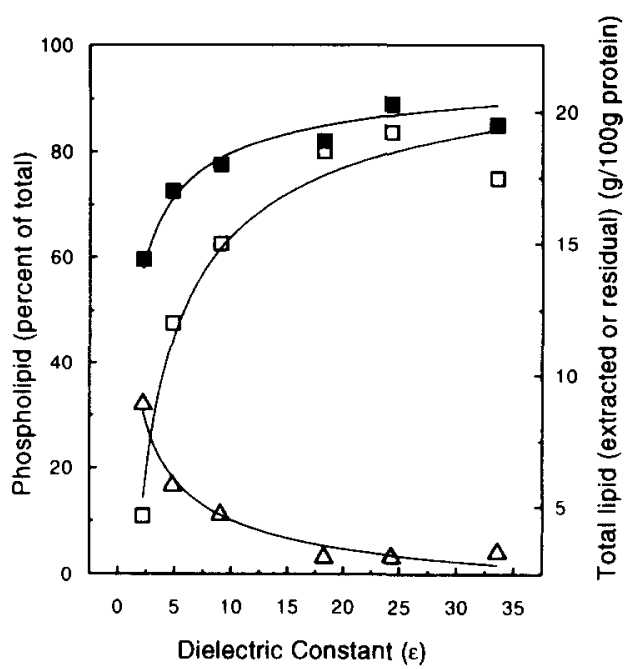

Fig. 1. Efficiency of lipid extraction from protein isolate according to the polarity of the solvent used in defatting. Average of three determinations of total extracted lipid $(\square)$, phospholipid

$(\square)$ and residual lipid determined by Folch wash $(\Delta)$.

the protein fraction and were easily removed by all solvents used. On the other hand, phospholipids were strongly bound to the protein and such interaction was disrupted only by high-polarity solvents. These characteristics might correspond to the patterns observed in Figs 1 and 2.

Circular dichroism spectra of the protein after lipid removal by the solvent treatment were partially equivalent. They were practically identical in the wavelength region $250-300 \mathrm{~nm}$, where tryptophan, phenylalanine and tyrosine contribute, indicating that the local environments for these amino acid residues were similar. Expanded recorded spectra in this region showed little variation samong samples, but there were significant changes in the region 190-250 $\mathrm{nm}$. Figure 3 shows typical spectra of carbon tetrachloride and methanol. The results suggest that changes in protein secondary conformation may have occurred according to the solvent used. Attempts to calculate the percentages of $\alpha$ helix, $\beta$ sheet and aperiodic structures according to

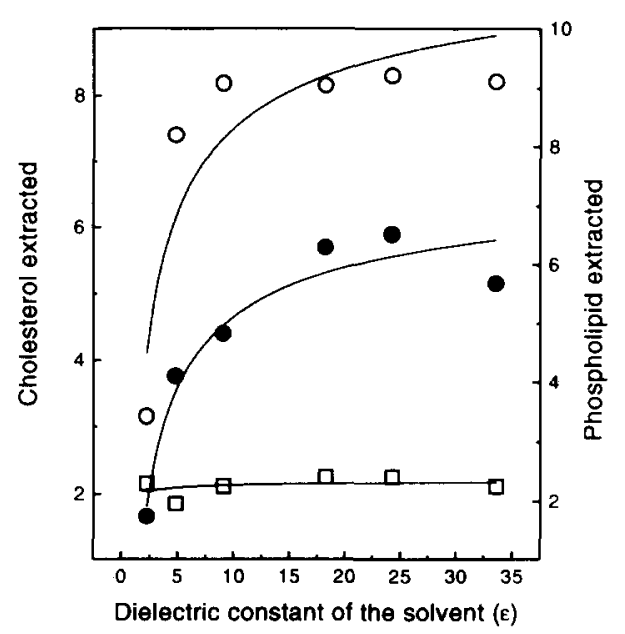

Fig. 2. Specificity of extraction of some lipid classes of lung isolates lipid fraction, according to the polarity of the solvent used in their defatting. Average of three determinations of extracted cholesterol $(\square)$, sphingomyelin $(O)$ and phosphatidylcholine $(O)$. 


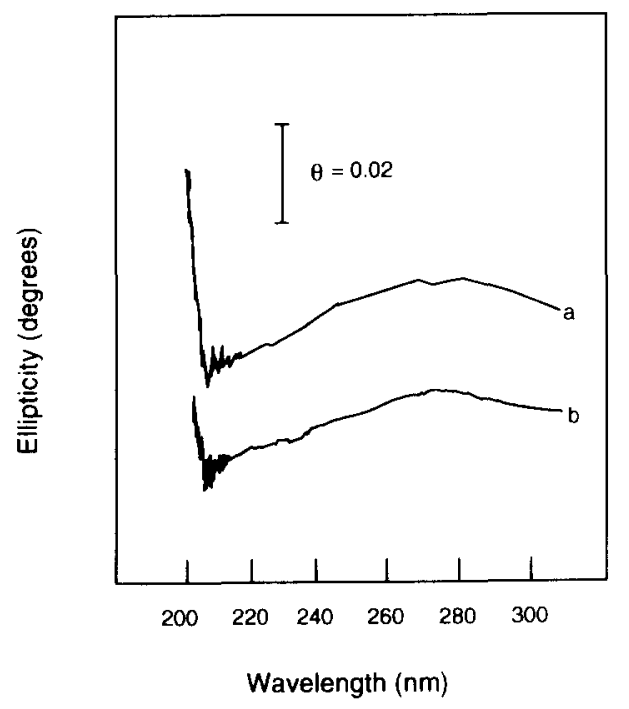

Fig. 3. Circular dichroism spectra of protein from isolates defatted by (a) carbon tetrachloride and (b) methanol.

Chen et al. (1972) resulted in large experimental errors, as a result of the insensitivity of the equipment, which produced intense noise in the spectra in the region below $220 \mathrm{~nm}$. Ellipticity at $222 \mathrm{~nm}$ can, however, provide an estimate of ordered structures such as $\alpha$ helix and $\beta$ sheet conformation (Chen et al., 1972). Figure 4 shows the decreasing trend in ellipticity as more residual lipid was left after solvent extraction.

Figure 5 displays the water monolayer results for water absorption and affinity constant of the water towards the proteins, measured by application of the BET equation (Brunauer et al., 1938; Kuntz \& Kauzmann, 1974). The monolayer value, which represents a measure of the available hydrophilic sites for water binding on the protein surface (Lüscher-Mattli \& Rüegg, 1982), increased with the increase in the residual lipid left after solvent extraction. Affinity of water to the protein showed an opposite trend; this

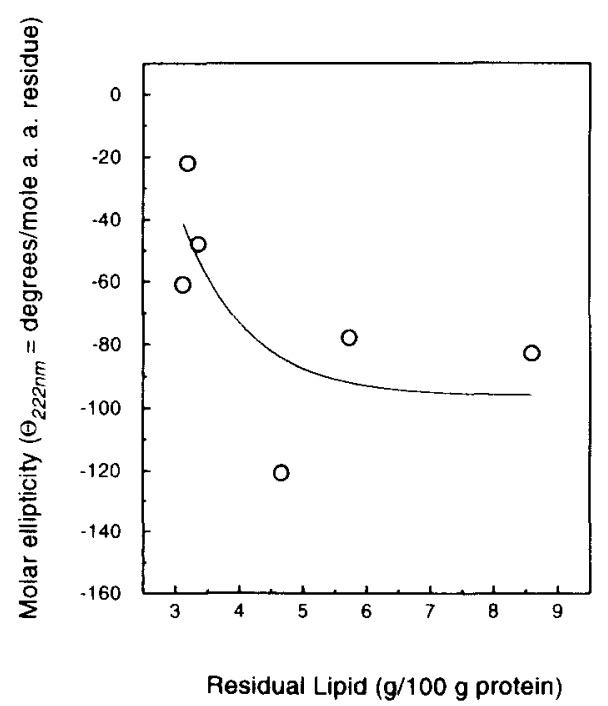

Fig. 4. Conformational changes observed on the protein after lipid removal from protein isolates, measured by circular dichroism (molar ellipticity $[\theta]=$ degrees/mmoles amino acid), as a function of the residual lipid left after solvent extraction (determined by Folch wash). Average of three determinations.

Total lipid content of the isolate is $20.45 \%$ (d.s.b.).

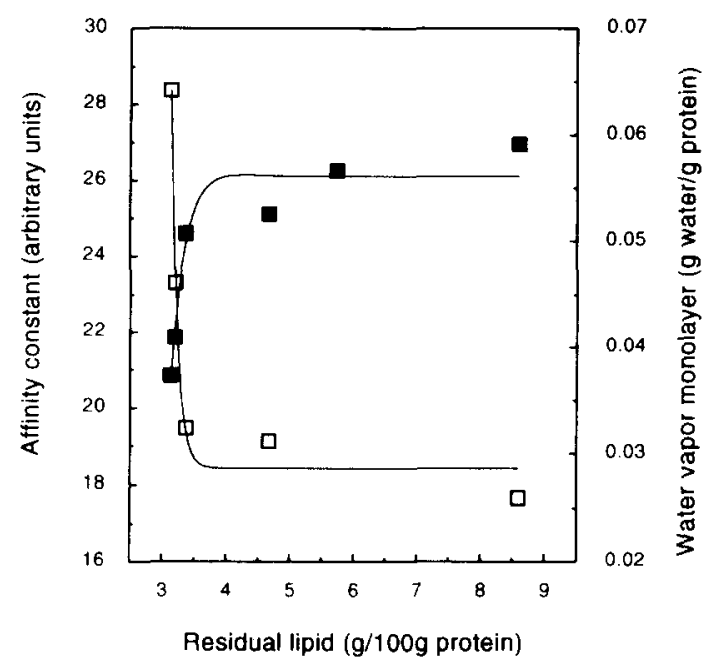

Fig. 5. Changes in ( $\square$ ) water monolayer on the protein surface and $(\square)$ affinity of water to the protein (measured using BET equation), as a function of the residual lipid left after solvent extraction (determined by Folch wash). Average of three determinations. Total lipid content of the isolate is $20.45 \%$ (d.s.b.).

result indicates that these variables are related in a physical absorption type phenomenon, where the absorption energy of each site is dependent on the degree of coverage of the surface (Shaw, 1981).

Figure 6 shows the solubility profile and superficial hydrophobicity of the protein as a function of the residual lipid after solvent extraction. The amount of hydrophobic sites available for SDS binding on the protein surface was related to the amount of residual lipid after solvent extraction. A similar pattern is observed for the available hydrophilic sites measured by water monolayer values and shown in Fig. 5. Solubility of these defatted proteins varied in the same way, increasing with increase of the residual lipid content. Although these results may appear contradictory, as increase in hydrophobicity of a protein surface is usually associated with its unfolding and insolubilization;

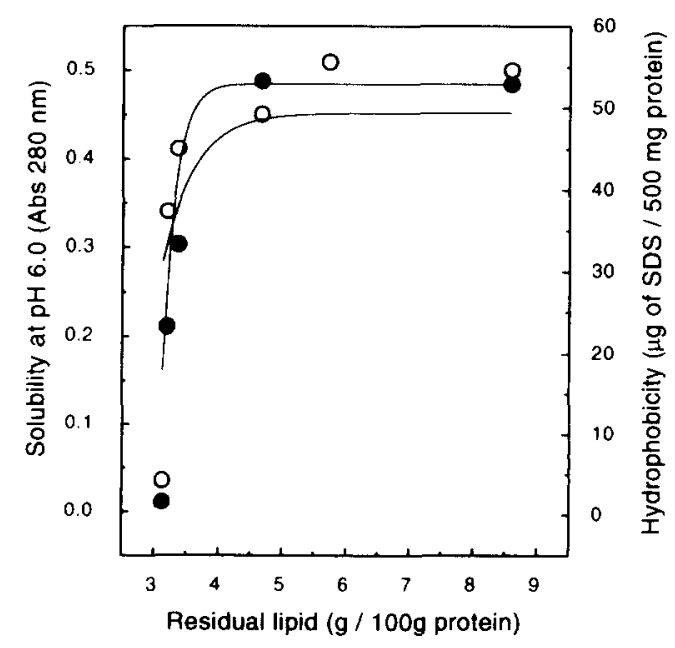

Fig. 6. Solubility $(O)$ and hydrophobicity $(O)$ of protein as a function of the residual lipid left after solvent extraction (determined by Folch wash). Average of three determinations. Total lipid content of the isolate is $20.45 \%$ (d.s.b.). 
proteins often present a high superficial hydrophobicity and high solubility, as has been found for bovine serum albumin (Nakai et al., 1980). This is due to the high rigidity of the protein molecule and the high content of hydrophilic amino acid residues on the molecule surface between the hydrophobic patches.

The results presented in Figs $4-6$ indicate that the presence of lipids in the isolates was an important aspect for protein functionality and conformation. As more residual phospholipid remained after lipid extraction, more ordered structures were observed, more hydrophilic and hydrophobic sites of the protein were exposed, and protein solubility was greater. The behaviour observed was probably not caused by the effect of the organic solvents used on the protein but by the lipid removal. Organic solvent action on protein would show an opposite trend, as less denaturation of the protein would occur as polarity of the solvent increased. These results agreed with the observation that phospholipids can induce a greater content of $\alpha$ helix conformation in protein structure (Kennedy et al., 1990; Takahashi et al., 1990). They also showed that the presence of lipids avoided organic solvent interaction with protein in the expected way. The observed effects of organic solvents on protein in these systems are similar to those of a preliminary report of brain lipidprotein complexes treated with several organic solvents (Carmona et al., 1988), where less denaturation of the protein was observed as polarity of the solvent decreased. In that report, and in the present work, lipid was present in high initial concentration in the samples.

\section{ACKNOWLEDGEMENTS}

The authors are grateful for scholarships from CAPES and CNPq, and financial support from FAPESP and FINEP. The use of the CD Spectropolarimeter of IQ-USP is acknowledged as well as the technical assistance offered by Dr A. Faljoni-Alário.

\section{REFERENCES}

Alcocer, M. J. C. \& Arêas, J. A. G. (1990). Lipid composition and hydration characteristics of lung protein isolates defatted by several solvents. J. Food Sci., 55, 19-25.

Arêas, J. A. G. (1985). Lipid-protein interactions in offal protein isolates: effects of several solvents on lipid extraction. J. Food Sci., 50, 1392-8.

Arêas, J. A. G. (1986a). Effect of lipid-protein interactions on hydration characteristics of defatted offal protein isolates. J. Food Sci., 51, 880-3.

Arêas, J. A. G. (1986b). Hydrophobic and electrostatic interactions on extrusion of protein isolates. J. Food Sci., 51, 1311-13.

Arêas, J. A. G. \& Lawrie, R. A. (1984). Effect of lipidprotein interactions on extrusion of protein isolates. Meat Sci., 11, 275-99.

Arêas, J. A. G. \& Mota, E. M. A. (1990). Effect of partial lipid removal with several organic solvents on conformation and solubility of proteins from bovine lung. Lebensm. Wiss. Technol., 23, 49-51.
Bastos, D. H. M. \& Arêas, J. A. G. (1990). Lung proteins: effect of defatting with solvents and extrusion on some functional properties. Meat Sci., 28, 223-36.

Bastos, D. H. M., Domenech, C. H. \& Arêas, J. A. G. (1991). Optimization of extrusion cooking of lung proteins by response surface methodology. Int. J. Food Sci. Technol., 26, 403-8.

Baxter, C. F., Rouser, G. \& Simon, G. (1969). Variation among vertebrates of lung phospholipid class composition. Lipids. 4, $243-4$.

Brunauer, S., Emmet, P. H. \& Teller, E. (1938). Adsorption of gases in multimolecular layers. J. Am. Chem. Soc., 60, $309-19$.

Bull, H. B. \& Breese, K. (1968). Protein hydration. I Binding sites. Arch. Biochem. Biophys., 128, 488-96.

Carmona, P., Diaz, R., Tandler, C. J. \& Monreal, J. (1988). In International Conference on Raman Spectroscopy, Vol. 11, John Wiley, Chichester, pp. 801-2.

Chen, Y. H., Yang, J. T. \& Martinez, H. M. (1972). Determination of the secondary structures of proteins by circular dichroism and optical rotary dispersion. Biochemistry, 11, $4120-31$.

Christie, W. W. (1982). Lipid Analysis. Pergamon Press, Oxford, $207 \mathrm{pp}$.

Courchaine, A. J., Miller, W. H. \& Stein, D. B. Jr (1959) Rapid semimicro procedure for estimating free and total cholesterol. Clin. Chem., 5, 609-14.

Dittmer, J. C. \& Lester, R. L. (1964). A simple specific spray for the detection of phospholipids on thin layer chromatograms. J. Lipid Res., 5, 126-7.

Folch, J., Lees, M. \& Sloane-Stanley, G. H. (1957). A simple method for the isolation and purification of total lipids from animal tissues. J. Biol. Chem., 226, 497-509.

Gault, N. F. S. \& Lawrie, R. A. (1980). Efficiency of protein extraction and recovery from meat industry by-products. Meat Sci., 4, 167-90.

Herkovits, T., Gadegbeku, G. \& Jahllet, H. (1970). On the structural stability and solvent denaturation of proteins. J. Biol. Chem., 245, 2588-99.

Kato, A., Kobayashi, K., Matsuda, T. \& Matsudomi, N. (1984). Determination of protein hydrophobicity using a sodium dodecyl-sulphate method. J. Agric. Food Chem., 32, 284-8.

Kennedy, D. F, Slotbloom, A. J., de Haas, G. H. \& Chapman, D. (1990). A Fourier-transform infrared spectroscopic (FTIR) study of porcine and bovine pancreatic phospholipase- $\mathrm{A}_{2}$ and their interactions with substrate analogs and a transition state inhibitor. Biochem. Biophys. Acta, 1040, 317-26.

Kuntz, I. D. Jr \& Kautzmann, W. (1974). Hydration of proteins. Adv. Prot. Chem., 28, 239 345.

Lawrie, R. A. (1991). Meat Science. Pergamon Press, Oxford, $293 \mathrm{pp}$.

Lepock, J. R., Rodahl, A. M., Zhang, C., Heynen, M. L., Waters, B. \& Cheng, K. H. (1990). Thermal denaturation of the $\mathrm{Ca}^{2+}$-ATPase of sarcoplasmic reticulum reveals two thermodynamically independent domains. Biochemistry, 29. 681-9.

Lüscher-Mattli, M. \& Rüegg, M. (1982). Thermodynamic functions of biopolymers hydration. I. Their determination by vapour pressure studies, discussed in an analysis of the primary hydration process. Biopolymers, 21, 403-8.

Nakai, S., Helbig, N., Ho, L., Kato, A. \& Tung, M. A. (1980). Relationship between hydrophobicity and emulsifying properties of some plant proteins. Can. Inst. Food Sci. Technol. J., 13, 23-5.

Rooney, S. A., Canavan, P. M. \& Motoyama, E. K. (1974). The identification of phosphatidylglycerol in the rat, rabbit, monkey and human lung. Biochim. Biophys. Acta, $360,56-67$.

Rouser, G., Fleischer, S. \& Yamamoto, A. (1970). Two dimensional thin layer chromatographic separation of 
polar lipids and determination of phospholipids by phosphorous analysis of spots. Lipids, 5, 494-6.

Russell, A. J., Groopman, J. D., Trudel, L. J., Skipper, P. L., Tannenbaun, S. R. \& Klibanov, A. M. (1989). Antibody-antigen binding in organic-solvents. Biochem. Biophys. Res. Commun., 158, 80-85.

Ryan, S. F., Hashim, A., Cernansky, G., Barret, C. R. \& Bell, A. L. L. (1980). Quantification of surfactant phospholipids in the dog lung. J. Lipid Res., 21, 1004-14.

Shaw, D. J. (1981). Introduction to Colloid and Interface Science. Butterworths, London, $265 \mathrm{pp}$.

Singer, S. L. (1962). The properties of proteins in nonaqueous solvents. Adv. Prot. Chem., 17, 1-68.

Singleton, W. S., Gray, M. S., Brown, M. L. \& White, J. L. (1965). Chromatographically homogenous lecithin from egg phospholipids. J. Am. Oil Chem. Soc., 42, 53-6.
Takahashi, A., Waring, J. A., Amirkhanian, J., Fan, B. \& Taeush, H. W. (1990). Structure-function relationship of bovine pulmonary surfactant proteins Sp-B and Sp-C. Biochim. Biophys. Acta, 1044, 43-9.

Weast, R. C. \& Astle, M. J. (1980). CRC Handbook of Chemistry and Physics, 61st ed. CRC Press, Boca Raton, FL, pp. E-55-E-60.

Whitaker, J. R. \& Feeney, R. E. (1983). Chemical and physical modification of proteins by the hydroxide ion. CRC Crit. Rev. Food Sci. Nutr, 19, 173-212.

Wuthier, R. E. (1966). Purification of lipids from nonlipid contaminants on Sephadex bead column. J. Lipid Res., 7, $558-68$.

Zaks, A. \& Klibanov, A. M. (1984). Enzymatic catalysis in organic solvent at $100^{\circ} \mathrm{C}$. Science, 224, 1249-51. 